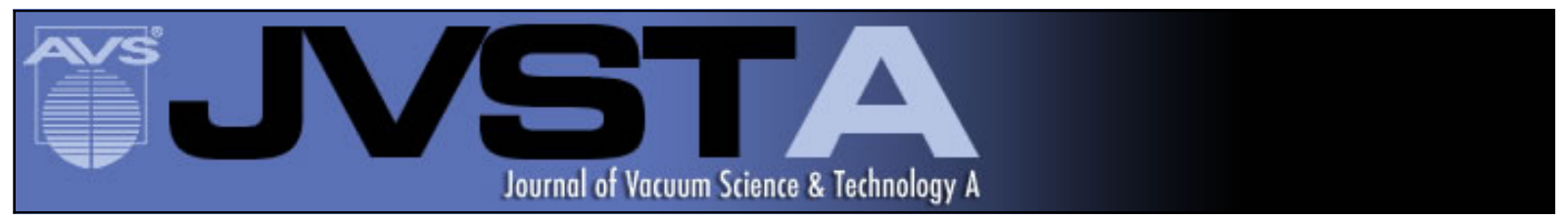

\title{
Plasma enhanced chemical vapor deposition of SiO2 using novel alkoxysilane precursors
}

K. H. A. Bogart, N. F. Dalleska, G. R. Bogart, and Ellen R. Fisher

Citation: Journal of Vacuum Science \& Technology A 13, 476 (1995); doi: 10.1116/1.579382

View online: http://dx.doi.org/10.1116/1.579382

View Table of Contents: http://scitation.aip.org/content/avs/journal/jvsta/13/2?ver=pdfcov

Published by the AVS: Science \& Technology of Materials, Interfaces, and Processing

\section{Articles you may be interested in}

Investigation of SiO2 plasma enhanced chemical vapor deposition through tetraethoxysilane using attenuated total reflection Fourier transform infrared spectroscopy

J. Vac. Sci. Technol. A 13, 2355 (1995); 10.1116/1.579521

Monte Carlo simulation of surface kinetics during plasma enhanced chemical vapor deposition of SiO2 using oxygen/tetraethoxysilane chemistry

J. Vac. Sci. Technol. A 11, 2562 (1993); 10.1116/1.578607

Determination of the mechanical stress in plasma enhanced chemical vapor deposited $\mathrm{SiO} 2$ and $\mathrm{SiN}$ layers

J. Vac. Sci. Technol. B 11, 614 (1993); 10.1116/1.586809

Planarization of $\mathrm{SiO} 2$ films using reactive ion beam in plasma enhanced chemical vapor deposition

J. Appl. Phys. 69, 6637 (1991); 10.1063/1.348878

Atomic structure in $\mathrm{SiO} 2$ thin films deposited by remote plasma-enhanced chemical vapor deposition

J. Vac. Sci. Technol. A 7, 1136 (1989); 10.1116/1.576242

\section{ADVERTISEMENT}

\section{Instruments for advanced science}
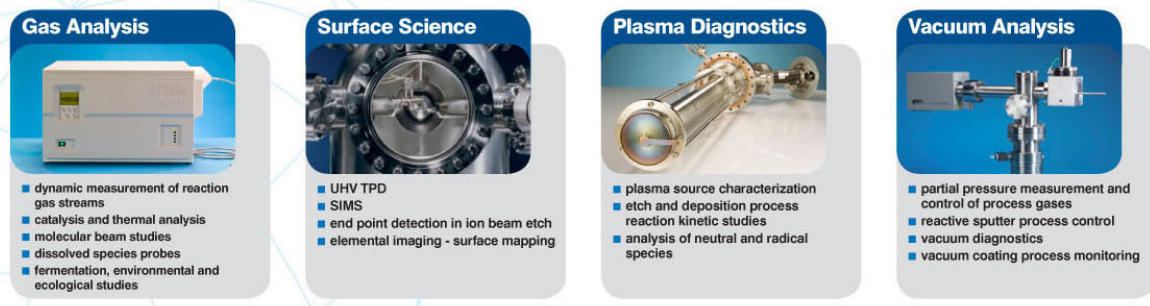

contact Hiden Analytical for further details

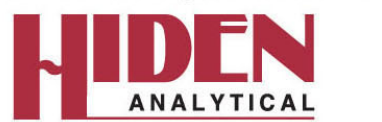

info@hideninc.com

www.HidenAnalytical.com

CLICK to view our product catalogue 


\title{
RAPID COMMUNICATIONS
}

This section is reserved for short submissions which contain important new results and are intended for accelerated publication.

\section{Plasma enhanced chemical vapor deposition of $\mathrm{SiO}_{2}$ using novel alkoxysilane precursors}

\author{
K. H. A. Bogart and N. F. Dalleska \\ Department of Chemistry, Colorado State University, Fort Collins, Colorado 80523 \\ G. R. Bogart \\ BioStar Inc., Boulder, Colorado 80301 \\ Ellen R. Fisher \\ Department of Chemistry, Colorado State University, Fort Collins, Colorado 80523
}

(Received 10 November 1994; accepted 10 December 1994)

\section{INTRODUCTION}

Plasma enhanced chemical vapor deposition (PECVD) is widely used in the microelectronics industry to deposit thin films. ${ }^{1}$ Dielectric materials such as silicon dioxide $\left(\mathrm{SiO}_{2}\right)$ are often deposited by PECVD for use as gate oxides, ${ }^{2,3}$ intermetal dielectrics, ${ }^{4}$ or passivation layers for integrated circuits. ${ }^{5,6}$ The main advantage of PECVD over other deposition methods such as thermal $\mathrm{CVD}^{7}$ is that deposition of good quality $\mathrm{SiO}_{2}$ can be performed at low substrate temperatures $\left(<350{ }^{\circ} \mathrm{C}\right)$ from $\mathrm{SiH}_{4} / \mathrm{O}_{2}$ or $\mathrm{SiH}_{4} / \mathrm{N}_{2} \mathrm{O}$ plasmas. ${ }^{8-10}$ These gas mixtures, however, are not desirable due to the pyrophoric nature of silane and problems with nitrogen contamination from $\mathrm{N}_{2} \mathrm{O}$.,11

Organosilanes, such as tetraethoxysilane (TEOS), have been used since the 1960 s to deposit $\mathrm{SiO}_{2}$ by PECVD. ${ }^{12-14}$ In addition to containing silicon and oxygen in a single molecule, TEOS has reduced toxicity and hazard compared to more conventional sources. ${ }^{5,7}$ Furthermore, TEOS provides better conformality and void free films with superior step coverage even at geometries less than $0.5 \mu \mathrm{m} .{ }^{5,15,16}$ These films also retain good mechanical and electrical properties at these dimensions. ${ }^{15}$ Although $\mathrm{SiO}_{2}$ films deposited from pure TEOS show hydrocarbon incorporation in this film, addition of an oxidant such as $\mathrm{O}_{2}$ or $\mathrm{O}_{3}$ eliminates this film contaminant. ${ }^{11,17}$

Here, we report the use of an inductively coupled rf plasma reactor to deposit $\mathrm{SiO}_{2}$ films from pure TEOS. We have also been successful in depositing $\mathrm{SiO}_{2}$ from the alkoxysilane precursors triethoxysilane (TriEOS), tetramethoxysilane (TMOS), and trimethoxysilane (TriMOS). These studies were undertaken for a number of reasons. First, to our knowledge, these precursors have not previously been used for PECVD of $\mathrm{SiO}_{2}$. Thus, we wished to ascertain whether $\mathrm{SiO}_{2}$ could be deposited from these starting materials. Second, we wanted to explore the effects of various deposition parameters on deposition rates, film refractive index, and film composition. Third, we were interested in determining whether changing the number and type of functional groups in the precursor would affect the film's properties. For example, Does decreasing the number of alkoxy substituents decrease the amount of hydrocarbon incorporation in the films? Hydrocarbon incorporation in the $\mathrm{SiO}_{2}$ film is not desirable because it will alter the mechanical and electrical properties of the film. Does the presence of an $\mathrm{Si}-\mathrm{H}$ moiety in the precursor produce films containing residual $\mathrm{Si}-\mathrm{H}$ bonds? The optical and electronic properties of the deposited materials could be strongly affected by the hydrogen content in the films. ${ }^{18}$ Finally. we are interested in the mechanism of $\mathrm{SiO}_{2}$ film deposition. By changing the starting materials systematically, we hoped to shed light on the process by which $\mathrm{SiO}_{2}$ is formed from alkoxysilanes.

This communication describes our results using these novel alkoxysilane precursors for PECVD of $\mathrm{SiO}_{2}$ films in an inductively coupled rf plasma reactor. The effects of deposition time, rf power, and organosilane pressure on the films' characteristics are described.

\section{EXPERIMENT}

An inductively coupled rf plasma reactor, Fig. 1, was built from two glass tubes with $50 \mathrm{~mm}$ O-ring joints, allowing easy access to the interior of the plasma chamber. The chamber is pumped by an Edwards two-stage rotary vane pump $(140 \ell / \mathrm{s})$. An eight turn, nickel plated copper coil is used to couple $13.56 \mathrm{MHz}$ rf power to the chamber and is tuned with a Jennings $100 \mathrm{pF}$ variable capacitor, Fig. 1. The alkoxysilanes $\left(25.5 \pm 0.5^{\circ} \mathrm{C}\right)$ was admitted into the plasma chamber through a heated $\left(39-56{ }^{\circ} \mathrm{C}\right)$ line. The vapor pressure was controlled using a Nupro bellows-sealed metering valve. The pressure in the chamber was monitored with an MKS Baratron capacitance manometer which is insensitive to differing gas compositions.

$p$-type silicon wafers (1-0-0 crystallization orientation) with 40-60 A native oxide were used as substrates. Freshly cleaned and polished sodium chloride $(\mathrm{NaCl})$ window substrates were also used. The substrates were placed on glass slides and oriented parallel to gas flow in the plasma chamber. Both a silicon wafer and a $\mathrm{NaCl}$ window were used for each deposition. Deposition times ranged from 0.5 to 10.0 min and were defined by when the rf power was applied. Power dependence measurements were made by varying the 


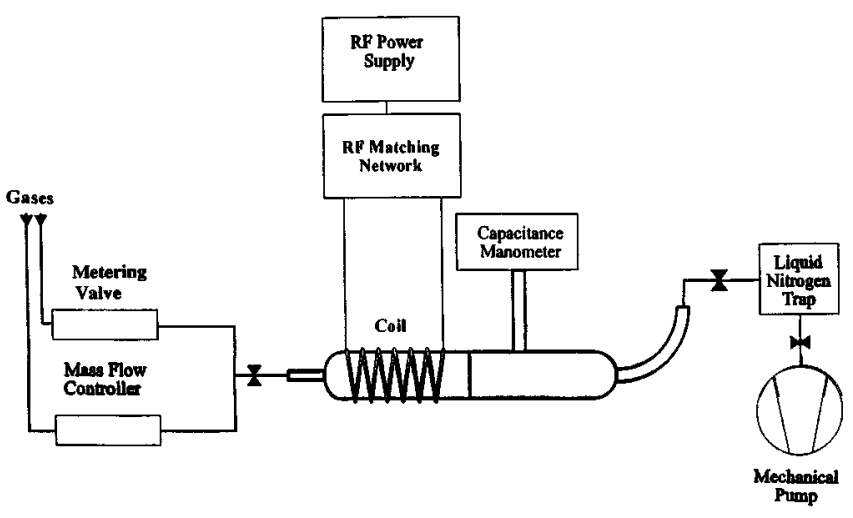

FIG. 1. Schematic diagram of the inductively coupled plasma reactor apparatus used for plasma deposition of $\mathrm{SiO}_{2}$.

rf power from 20 to $90 \mathrm{~W}$. For each measurement, deposition time was kept at 5 min for TMOS, TriMOS, and TriEOS. Three min depositions were used for TEOS due to its faster deposition rate. Pressure was varied from 20 to 32 mTorr by throttling the valve between the plasma chamber and the liquid nitrogen trap, Fig. 1. For each alkoxysilane introduced into the plasma chamber, the pressure was allowed to stabilize prior to application of the $\mathrm{rf}$ power. All of the alkoxysilanes $(>95 \%$ pure) were purchased from United Chemical Technology and were used without further purification except for multiple freeze-pump-thaw cycles.

Substrates were removed from the plasma chamber for analysis. Transmission spectra for the $\mathrm{NaCl}$ substrates were obtained with a Nicolet 5PC Fourier transform infrared
(FTIR) spectrometer. Spectra shown were not manipulated unless specifically noted. Absolute absorbance values were obtained by converting transmission spectra to absorbance and performing a baseline correction on the spectra with a second order polynomial. Film thicknesses and refractive indices were calculated from ellipsometric analyses at 632.8 $\mathrm{nm}$ using a Gaertner L116A automatic null ellipsometer.

\section{RESULTS AND DISCUSSION}

Figure 2(A) shows a typical FTIR spectrum of a $\mathrm{SiO}_{2}$ film deposited in our reactor with $100 \%$ TEOS. The absorbance bands at 2977, 2930, and $2898 \mathrm{~cm}^{-1}$ are assigned to $\mathrm{C}-\mathrm{H}$ stretches from aliphatic- $-\mathrm{CH}_{3},-\mathrm{CH}_{2}$, and $-\mathrm{CH}$ groups, respectively. ${ }^{19,20}$ The weak absorbances at 1445 and 1391 $\mathrm{cm}^{-1}$ are the asymmetric and symmetric $\mathrm{C}-\mathrm{H}$ bending of $-\mathrm{CH}_{3}$ groups. ${ }^{19,20}$ The most intense absorbance band at 1078 $\mathrm{cm}^{-1}$ is due to $\mathrm{Si}-\mathrm{O}-\mathrm{C}$ and linear $\mathrm{Si}-\mathrm{O}-\mathrm{Si}$ groups. ${ }^{19,20} \mathrm{Ab}-$ sorbance peaks at 967,884 , and $795 \mathrm{~cm}^{-1}$ are more difficult to identify. Assignments in the literature include $\mathrm{Si}-\mathrm{OH}$ and $\mathrm{Si}-\mathrm{O}-\mathrm{CH}_{2} \mathrm{CH}_{3}$ for the $967 \mathrm{~cm}^{-1}$ band, $\mathrm{Si}-\mathrm{H}$ and $\mathrm{Si}-\mathrm{C}$ for the $884 \mathrm{~cm}^{-1}$ band, and $\mathrm{Si}-\mathrm{O}-\mathrm{Si}$ and $\mathrm{Si}-\mathrm{O}-\left(\mathrm{CH}_{3}\right)_{x=1,2}$ for the $795 \mathrm{~cm}^{-1}$ band. ${ }^{17,19-21}$ The doublet at 2342 and 2359 $\mathrm{cm}^{-1}$ is due to residual carbon dioxide not purged from the FTIR spectrometer. The spectra for $\mathrm{SiO}_{2}$ films deposited from TEOS in our reactor are very similar to those found in the literature. ${ }^{17,21}$

Figure 2(B) shows a FTIR spectrum for the $\mathrm{SiO}_{2}$ film deposited with a $100 \%$ TriEOS plasma. The spectral features are very similar to those of the film deposited from TEOS with respect to the aliphatic hydrocarbon and silicon oxide absorbance peaks, Fig. 2(A). The most noticeable difference

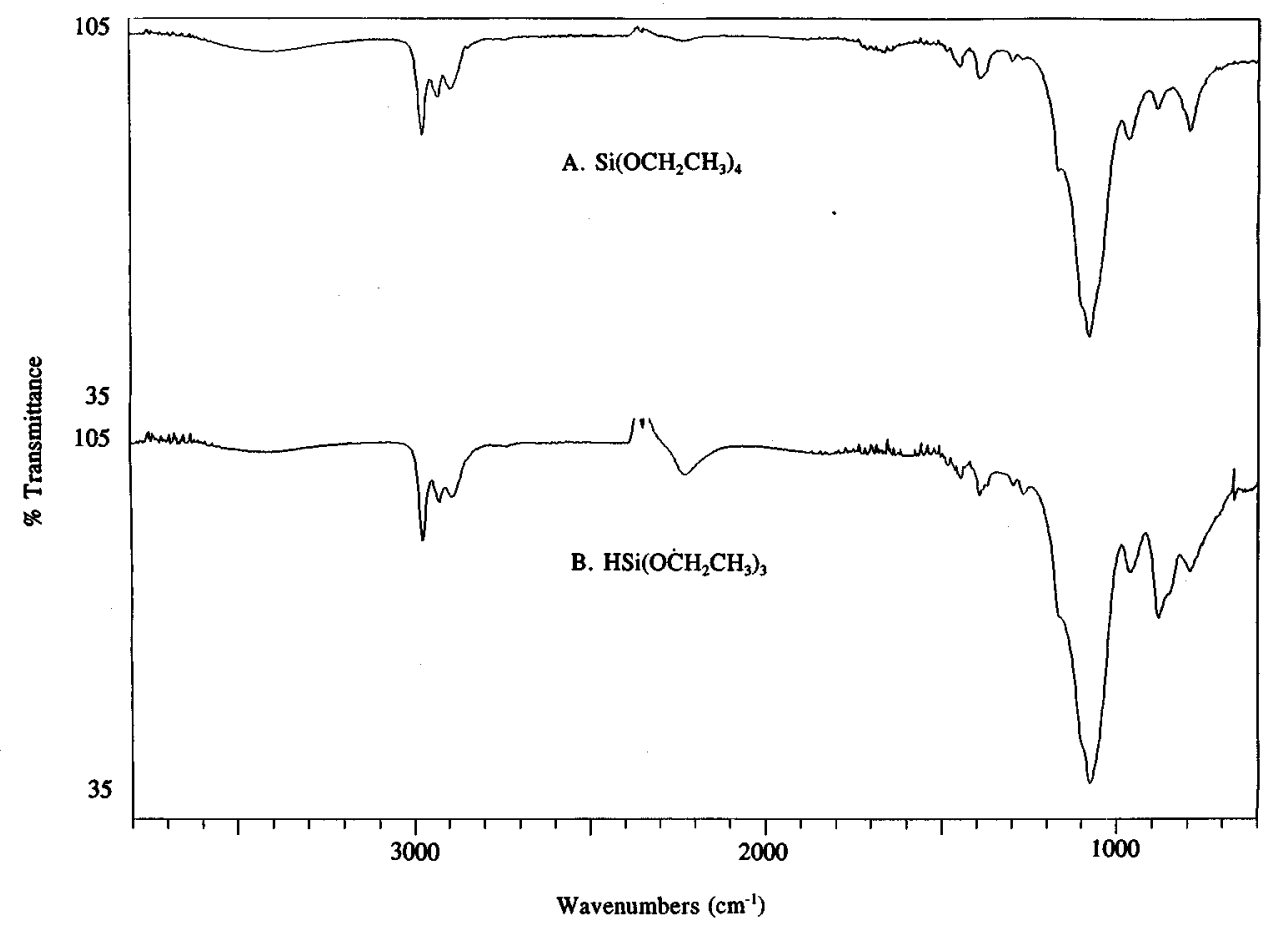

FIG. 2. FTIR transmission spectra of films deposited on $\mathrm{NaCl}$ windows using (A) 100\% TEOS and (B) 100\% TriEOS. A baseline correction with a second-order polynomial was performed on the TriEOS spectrum. Deposition conditions for these spectra are given in Table I. 


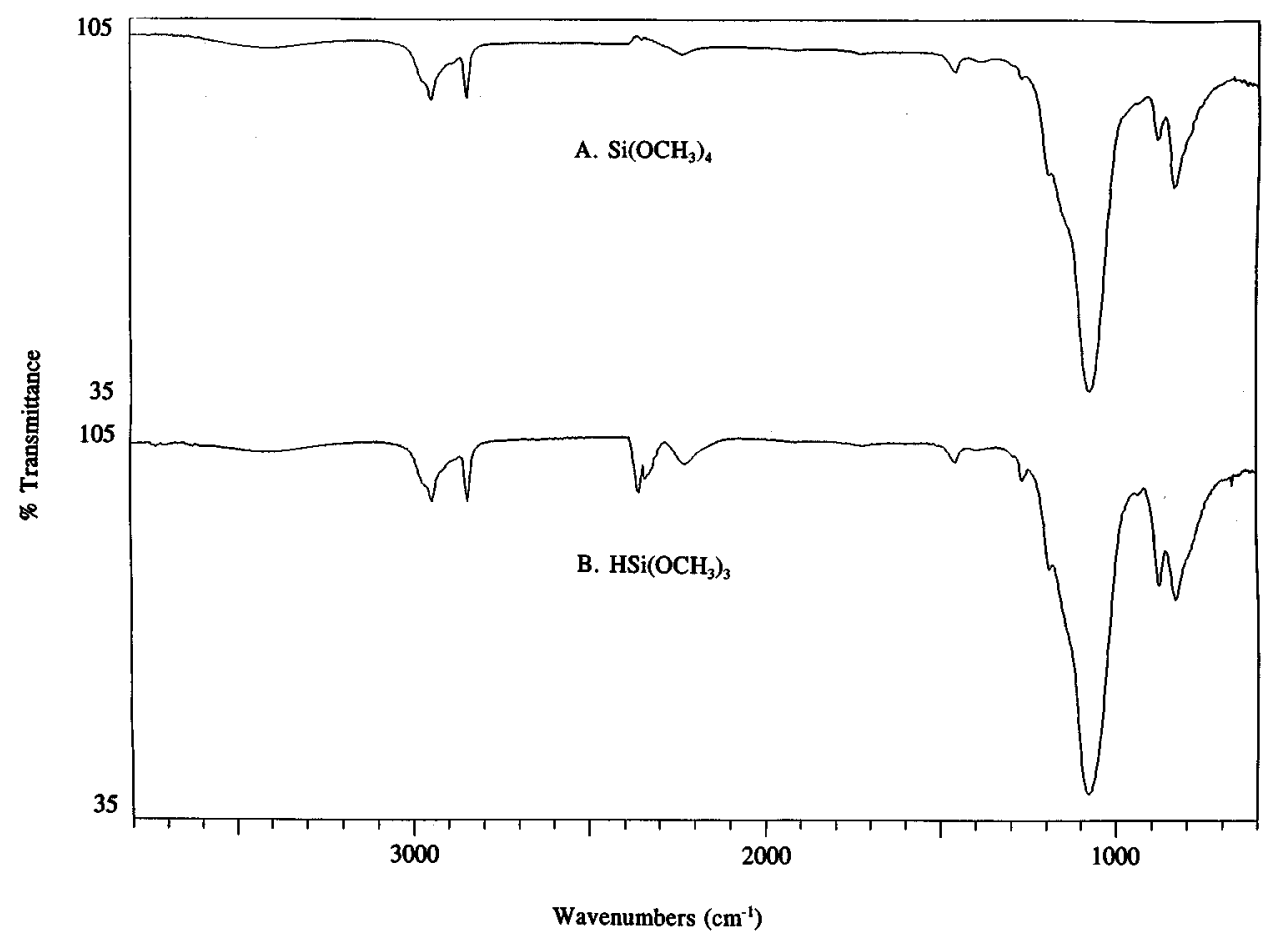

FIG. 3. FTIR transmission spectra of films deposited on $\mathrm{NaCl}$ windows using (A) 100\% TMOS and (B) $100 \%$ TriMOS. Deposition conditions for these spectra are given in Table I.

is the presence of the $\mathrm{Si}-\mathrm{H}$ stretching absorbance at 2230 $\mathrm{cm}^{-1} \cdot{ }^{19-21}$ This absorbance band is not seen with TEOS, Fig. 2(A). The other significant difference is the increased intensity for the absorbance peak at $880 \mathrm{~cm}^{-1}$ and the presence of a shoulder at a lower frequency.

The FTIR spectrum for a film deposited from a $100 \%$ TMOS plasma is shown in Fig. 3(A). Again, the spectral features are similar to those for TEOS films, indicating we have deposited $\mathrm{SiO}_{2}$. There are, however, a few notable differences in the two spectra. The most marked change is the absence of the aliphatic $\mathrm{C}-\mathrm{H}$ stretching vibration for the $-\mathrm{CH}_{2}$ group. Other changes include the presence of a very weak $\mathrm{Si}-\mathrm{H}$ absorbance peak at $2230 \mathrm{~cm}^{-1}$, the absence of the $\mathrm{Si}-\mathrm{O}$ absorbance peak near $980 \mathrm{~cm}^{-1}$, and an additional absorbance peak at $835 \mathrm{~cm}^{-1}$.
Figure 3(B) shows the FTIR spectrum of the film deposited from a $100 \%$ TriMOS plasma. The spectral features are nearly identical to those for the film deposited from TMOS, again indicating that we are indeed depositing $\mathrm{SiO}_{2}$. The $\mathrm{Si}-\mathrm{H}$ stretching vibration is observed in this film, similar to films using TriEOS as a precursor, Fig. 2(B). The absorbance peak intensity at $2230 \mathrm{~cm}^{-1}$ is much greater for TriMOS than for TMOS, but is almost equal in intensity to that for the TriEOS film.

Table I lists deposition rates and refractive indices for $\mathrm{SiO}_{2}$ films deposited from TEOS, TriEOS, TMOS, and TriMOS in our reactor at the deposition conditions noted in Table I. Deposition rates for the ethoxysilanes are greater than $978 \AA$ 解, while those for the methoxysilanes are much lower at $<790 \AA / \mathrm{min}$. We have not found any pub-

TABLE I. Deposition rates, refractive indices, and FTIR absorbance values for $\mathrm{SiO}_{2}$ films. ${ }^{\mathrm{a}}$

\begin{tabular}{|c|c|c|c|c|c|c|c|c|c|}
\hline \multirow[b]{2}{*}{ Alkoxysilane } & & \multirow{2}{*}{$\begin{array}{l}\text { Deposition rate } \\
(\AA \AA \mathrm{min})\end{array}$} & \multirow{2}{*}{$\begin{array}{l}\text { Refractive } \\
\text { index }\end{array}$} & \multicolumn{5}{|c|}{ FTIR absorbance values ${ }^{b}$} & \multirow[b]{2}{*}{$\mathrm{SiO} / \mathrm{CH}_{3}$} \\
\hline & & & & $\mathrm{CH}_{3}$ & $\mathrm{CH}_{2}$ & $\mathrm{CH}$ & $\mathrm{SiO}$ & $\mathrm{SiH}$ & \\
\hline \multirow[t]{2}{*}{ TEOS } & Avg & 1360 & 1.463 & 6.6 & 3.4 & 3.1 & 27.1 & 0.0 & 4.14 \\
\hline & $s_{d}$ & 111.3 & 0.0047 & 0.7 & 0.6 & 0.6 & 0.7 & 0.0 & 0.477 \\
\hline \multirow[t]{2}{*}{ TriEOS } & Avg & 1060 & 1.459 & 7.8 & 4.5 & 4.0 & 35.4 & 1.8 & 4.59 \\
\hline & $s_{d}$ & 73.3 & 0.0017 & 0.9 & 0.6 & 0.5 & 1.8 & 0.2 & 0.331 \\
\hline \multirow[t]{2}{*}{ TMOS } & Avg & 610.7 & 1.450 & 4.2 & 0.0 & 4.0 & 36.2 & 0.2 & 8.56 \\
\hline & $s_{d}$ & 109.5 & 0.0155 & 0.6 & 0.0 & 0.7 & 4.8 & 0.2 & 0.168 \\
\hline \multirow[t]{2}{*}{ TriMOS } & Avg & 745.7 & 1.446 & 4.5 & 0.0 & 4.5 & 37.9 & 1.2 & 8.42 \\
\hline & $s_{s_{d}}$ & 38.8 & 0.002 & 0.2 & 0.0 & 0.2 & 1.6 & 0.3 & 0.031 \\
\hline
\end{tabular}

${ }^{a}$ These films were all deposited under the following deposition conditions: $r f$ input power $=50 \mathrm{~W}$; reactor pressure $=28-48 \mathrm{mTorr}$; deposition time $=3 \mathrm{~min}$ for TEOS, $5 \mathrm{~min}$ for other alkoxysilanes. Values given are averages of three independent depositions. Standard deviations are given, $s_{d}$.

${ }^{\mathrm{b}}$ Absorbance $\times 10^{-2}$. 
lished deposition rates for 100\% TEOS depositions; however, our deposition rates are equal to or greater than deposition rates published for TEOS $/ \mathrm{O}_{2}$ plasma depositions. ${ }^{3,12,20}$ The refractive indices for TEOS and TriEOS films, Table I, are identical to published values for chemically deposited $\mathrm{SiO}_{2}, 1.44$ to $1.46 .{ }^{1}$ Our values also agree with literature values for the refractive index of $\mathrm{SiO}_{2}$ films deposited by PECVD from TEOS, which vary from 1.45 to 1.55 . ${ }^{1}$ The $\mathrm{SiO}_{2}$ films grown from TMOS and TriMOS have refractive indices in the same range, 1.450 and 1.446, respectively. Variations in refractive index may be due to film species other than $\mathrm{SiO}_{2}$. For example, the refractive index of noncrystalline $\mathrm{Si}-\mathrm{O}$ is approximately 1.95 at $633 \mathrm{~nm}$ (Ref. 22) and is 1.4 to 1.5 for hydrocarbons. ${ }^{23}$ Our measured refractive indices could be a combination of values for various species in the deposited film.

Also listed in Table I are the FTIR absorbance values for the $-\mathrm{CH}_{3},-\mathrm{CH}_{2}, \mathrm{Si}-\mathrm{O}$, and $\mathrm{Si}-\mathrm{H}$ stretching absorption bands and the ratio of the $\mathrm{Si}-\mathrm{O}$ to $-\mathrm{CH}_{3}$ absorbance values for the depositions performed with all four alkoxysilanes. The absolute absorbance values for the $\mathrm{Si}-\mathrm{O}$ peaks are greater for the methoxysilanes than for the ethoxysilanes by approximately $15 \%$. The values of the $-\mathrm{CH}_{3}$ absorbance peak are nearly $40 \%$ less for the methoxysilanes compared to the ethoxysilanes. Furthermore, the methylene absorbance at $2930 \mathrm{~cm}^{-1}$ is present in the ethoxysilane films but is absent in the methoxysilane films. As noted above, the films deposited from trialkoxysilanes show a marked increase in the values of the $\mathrm{Si}-\mathrm{H}$ absorbance at $2230 \mathrm{~cm}^{-1}(\sim 0.015 \mathrm{abs})$ as compared to that for films deposited from the tetraalkoxysilanes $(\sim 0.002 \mathrm{abs})$. The ratio of the $\mathrm{Si}-\mathrm{O}$ to $-\mathrm{CH}_{3}$ absorbance values is approximately 4.4 for the ethoxysilanes and is 8.5 for the methoxysilanes. From these data, we conclude that the $\mathrm{SiO}_{2}$ films grown from the methoxysilanes have a smaller degree of hydrocarbon incorporation than those grown from the ethoxysilanes. The lesser amount of carbon and hydrogen in the methyl substituent may simply give less hydrocarbon incorporation in the $\mathrm{SiO}_{2}$ films.

Deposition time, rf power, and alkoxysilane pressure were varied to determine each of their effects on deposition rate, refractive index, and FTIR absorbance values for the $-\mathrm{CH}_{3}$, $-\mathrm{CH}_{2}$, and $\mathrm{Si}-\mathrm{O}$ peaks. Although we do not explicitly show all these data here, we will discuss the trends observed in varying these plasma parameters. ${ }^{24} \mathrm{We}$ found that as deposition time increases, deposition rates decrease slightly and appear to level off for all four alkoxysilanes. This pattern may indicate that a steady state deposition is not immediate in the plasma reactor but is achieved within a few minutes. Published data for TEOS $/ \mathrm{O}_{2}$ plasmas show the deposition rate to be independent of deposition time over a time range of several minutes to hours. ${ }^{13,14,20}$ Our high deposition rate, $\sim 1360 \AA / \mathrm{min}$ for TEOS, allows us to study deposition rates at times less than $10 \mathrm{~min}$. As deposition time is increased, the refractive indices for the four alkoxysilanes remain constant. Absorbance values for the alkane and silicon oxide bands increase as deposition time increases, indicating a thicker film. There is not a significant change in the ratio of $\mathrm{Si}-\mathrm{O}$ to $-\mathrm{CH}_{3}$ absorbance values with increased deposition time.

As the rf power is increased, deposition rates of the four

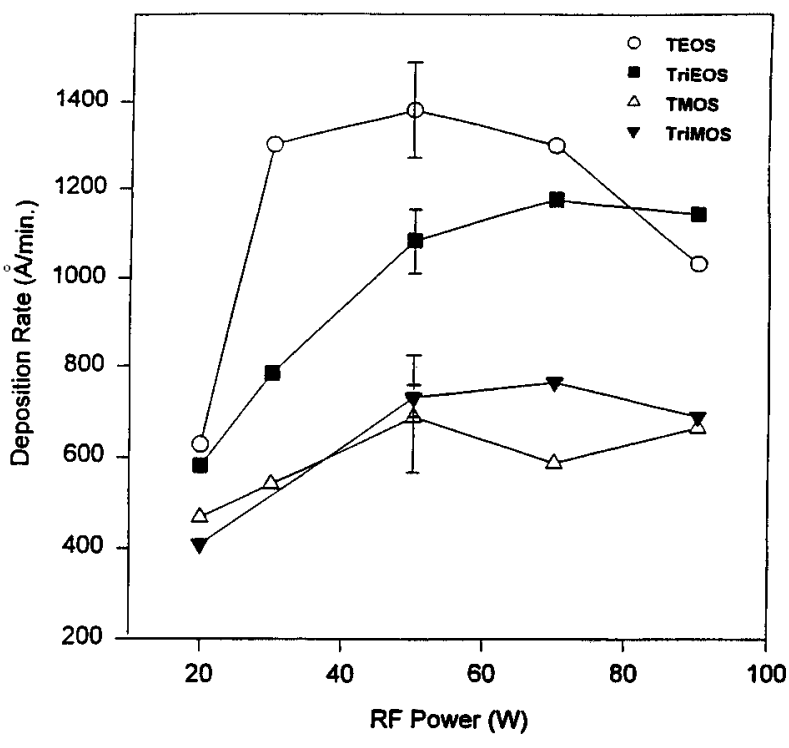

FIG. 4. Relation between rf input power and deposition rate for the four alkoxysilanes used to deposit $\mathrm{SiO}_{2}$ films. Open circles are data for the TEOS depositions, closed squares are for the TriEOS depositions, open triangles are for TMOS depositions, and closed, inverted triangles are for TriMOS depositions. Vertical lines represent the standard deviation in the experimental values. Deposition conditions for all four alkoxysilanes were essentially the same, Table I.

alkoxysilanes increase and tend to level off or decrease, Fig. 4. Maxima for the curves indicate an optimal power to maximize deposition rate. For TEOS plasmas, the optimal rf power is between 30 and $70 \mathrm{~W}$. The other alkoxysilane plasmas maximize deposition rate between 50 and $90 \mathrm{~W}$ of $\mathrm{rf}$ power. Too low an rf power may not create as many reactive species for deposition. At higher rf powers, the deposition rate does not continue to increase. At these higher powers, the reaction may be limited by other factors in the system such as decomposition of the reactive species in the plasma chamber. The index of refraction of the deposited $\mathrm{SiO}_{2}$ films remains constant as rf power is varied from 20 to $90 \mathrm{~W}$. The FTIR absorbance values for the alkane and silicon oxide stretching absorption bands increase and then decrease as power increases. As rf power increases, absorbance values, hence film thickness, follows the same pattern as deposition rate, Fig. 4.

Changing the alkoxysilane pressure from 20 to 324 mTorr in the plasma chamber has little effect on the film characteristics investigated, including deposition rate and refractive index, for all four alkoxysilanes. Our results suggest that the alkoxysilane vapor pressure in our reactor is not a limiting factor for the deposition process. The FTIR absorbance values for the films also did not change significantly as pressure was varied.

These results show that $\mathrm{SiO}_{2}$ can indeed be deposited from these new alkoxysilane precursors. Subtle differences in the deposited films are, however, evident between the four alkoxysilanes studied and these differences give us insight into the deposition mechanism. For example, the FTIR spectra show the presence of a methylene absorbance in the films deposited from the ethoxysilanes. This absorbance is not present in the films deposited from the methoxysilanes. This 
indicates that the deposition process is not disrupting the methyl group to form a $-\mathrm{CH}_{2}$ moiety in the film. Furthermore, this could imply that the ethyl group from the ethoxysilanes is also left intact during deposition. Several studies in the literature hypothesize that the $\mathrm{C}-\mathrm{O}$ bonds in the alkoxysilanes are ruptured in the plasma forming $\mathrm{Si}-\mathrm{O}$ and $\mathrm{C}_{x} \mathrm{H}_{2 x-1}$ species. ${ }^{7,17}$ The $\mathrm{C}-\mathrm{O}$ bond $(100.9 \mathrm{kcal} / \mathrm{mol})$ is weaker than the $\mathrm{Si}-\mathrm{O}$ bond $(130.9 \mathrm{kcal} / \mathrm{mol}){ }^{25}$ Thus, this is a plausible decomposition pathway on the basis of thermochemical arguments. Thermal decomposition studies of TEOS also indicate that gas-phase decomposition products include organic fragments such as ethanol, ethylene, and methane. ${ }^{7,17,26}$ Our data support the hypothesis that the alkyl moieties are separated from the silicon oxygen group as the intact alkane radical.

Another important feature in our FTIR spectra is the $\mathrm{Si}-\mathrm{H}$ absorbance at $2230 \mathrm{~cm}^{-1}$. Fracassi et al. have reported the absence of the $\mathrm{Si}-\mathrm{H}$ absorbance band in their films deposited from $100 \%$ TEOS. ${ }^{17}$ In contrast, several other groups report the presence of a $\mathrm{Si}-\mathrm{H}$ absorbance band in the FTIR spectra of their TEOS and TEOS/O $\mathrm{O}_{2}$ plasma films. ${ }^{14,20,21}$ Our results do not show a distinct $\mathrm{Si}-\mathrm{H}$ absorbance for the tetraalkoxysilane films. The strong intensity of the $\mathrm{Si}-\mathrm{H}$ absorbance band does, however, indicate the presence of $\mathrm{Si}-\mathrm{H}$ species in the films formed from the trialkoxysilane precursors, Figs. 2(B) and 3(B). This implies that, although the $\mathrm{Si}-\mathrm{H}$ bond is relatively weak $(\sim 99 \mathrm{kcal} / \mathrm{mol})(\mathrm{Ref} .25)$ when compared to the $\mathrm{Si}-\mathrm{O}$ bond $(\sim 131 \mathrm{kcal} / \mathrm{mol}),{ }^{25}$ it is not completely dissociated in the plasma deposition process. It also suggests that $\mathrm{Si}-\mathrm{H}$ bonding in the films is not formed from the hydrogen atoms in the alkane substituents. This also supports the proposed deposition mechanism ${ }^{7,17,26}$ of preferentially breaking the $\mathrm{C}-\mathrm{O}$ bond in the alkoxysilane and producing $\mathrm{C}_{2} \mathrm{H}_{5}$ or $\mathrm{CH}_{3}$ radicals to breaking the $\mathrm{Si}-\mathrm{O}$ or $\mathrm{Si}-\mathrm{H}$ bonds.

\section{CONCLUSIONS}

In summary, we have deposited $\mathrm{SiO}_{2}$ films on silicon and $\mathrm{NaCl}$ substrates from TEOS and three novel alkoxysilanes, TriEOS, TMOS, and TriMOS. The films from all four alkoxysilanes have FTIR spectra and refractive indices similar to $\mathrm{SiO}_{2}$, and deposition rates are reasonably fast, $\sim 1360 \AA / \mathrm{min}$ for TEOS. As the size of the alkane substituent decreases, the amount of hydrocarbon incorporation in the films decreases. Films deposited with trialkoxysilanes show significant amounts of $\mathrm{Si}-\mathrm{H}$ bonding in their FTIR spectra, while those deposited from tetraalkoxysilanes do not. The methoxysilanes give films with a greater $\mathrm{SiO} / \mathrm{CH}_{3}$ ratio but at a slower deposition rate. Future investigations will continue to explore PECVD of $\mathrm{SiO}_{2}$ from novel alkoxysilane precursors, including $\mathrm{ClSi}\left(\mathrm{OC}_{2} \mathrm{H}_{5}\right)_{3}$.

\section{ACKNOWLEDGMENTS}

The support of the National Science Foundation under Grant No. DMR-9409272, Sandia National Laboratories under Contract No. AJ-3848 and Colorado State University through the Faculty Diversity Career Enhancement Fund and Faculty Research Grants is gratefully acknowledged.

${ }^{1}$ A. C. Adams, in Plasma Deposited Thin Films, edited by J. Mort and F. Jansen (Chemical Rubber, Boca Raton, 1986).

${ }^{2}$ G. W. Hills, A. S. Harris, and M. J. Thoma, Solid State Technol. April, 127 (1990).

${ }^{3}$ I. T. Emesh, G. D'Asti, J. S. Mercier, and P. Leung, J. Electrochem. Soc. 136, 3404 (1989).

${ }^{4}$ L. Chen, S. Hsia, and K. Chen, Jpn. J. Appl. Phys. 32, 6119 (1993).

${ }^{5}$ G. Tochitani, M. Shimozuma, and H. Tagashira, J. Vac. Sci. Technol. B 11, 400 (1993).

${ }^{6}$ A. Banerjee and T. DebRoy, J. Vac. Sci. Technol. B 10, 3395 (1992).

${ }^{7}$ J. E. Crowell, L. L. Tedder, H.-C. Cho, F. M. Cascarano, and M. A. Logan, J. Electron. Spectrosc. Rel. Phenom. 54/55, 1097 (1990).

${ }^{8}$ A. C. Adams, F. B. Alexander, C. D. Capio, and T. E. Smith, J. Electrochem. Soc. 28, 1545 (1981); S. V. Hattangady, R. G. Alley, G. G. Fountain, R. J. Markunas, G. Lucovsky, and D. Temple, J. Appl. Phys. 73, 7635 (1993).

${ }^{9}$ D. L. Smith and A. S. Alimonda, J. Electrochem. Soc. 140, 1496 (1993).

${ }^{10}$ S. W. Hsieh, C. Y. Chang, and S. C. Hus, J. Appl. Phys. 74, 2636 (1993).

${ }^{11}$ M. G. J. Veprek-Heijman, and D. Boutard, J. Electrochem. Soc. 138, 2042 (1991).

${ }^{12}$ E. B. Priestley and P. J. Call, Thin Solid Films 69, 39 (1980).

${ }^{13}$ D. R. Secrist and J. D. Mackenzie, J. Electrochem. Soc. 113, 914 (1966).

${ }^{14}$ S. W. Ing, Jr. and W. Davern, J. Electrochem. Soc. 112, 284 (1965).

${ }^{15}$ K. Maeda and S. M. Fisher, Solid State Technol. June, 83 (1993).

${ }^{16}$ A. S. Harrus, G. W. Hills, and M. J. Thoma, Pure Appl. Chem. 9, 1757 (1990).

${ }^{17}$ F. Fracassi, R. d'Agostino, and P. Favia, J. Electrochem. Soc. 139, 2636 (1992).

${ }^{18}$ N. M. Johnson, C. E. Nebel, P. V. Santos, W. B. Jackson, R. A. Street, K. S. Stevens, and J. Walker, Appl. Phys. Lett. 59, 1443 (1991).

${ }^{19}$ R. T. Conley, Infrared Spectroscopy (Allyn \& Bacon, Boston, MA, 1966).

${ }^{20}$ S. P. Mukherjee and P. E. Evans, Thin Solid Films 14, 105 (1972).

${ }^{21}$ U. Mackens and U. Merkt, Thin Solid Films 97, 53 (1982).

${ }^{22}$ Handbook of Optical Constants of Solids, edited by E. D. Palik (Academic, Orlando, 1985).

${ }^{23}$ Handbook of Chemistry and Physics, 63rd ed., edited by R. C. Weast (Chemical Rubber, Boca Raton, 1982).

${ }^{24} \mathrm{~A}$ more detailed presentation of this data will be given in a future publication. K. H. A. Bogart and E. R. Fisher (unpublished).

${ }^{25} \mathrm{P}$. Ho and C. F. Melius (unpublished).

${ }^{26}$ M. G. M. Van der Vis, E. H. P. Cordfunke, and R. J. M. Konings, J. Phys. (Paris) IV 3, 75 (1993) 